IN MEMORIAM

\title{
Bill McCormick (1942-2011)
}

Bill McCormick was larger than life. I confirmed this extravagant judgement in several spheres of his life and mine. As a resident he was indistinguishable from faculty members. When asked to document a new patient or someone in the clinic, he left no stone unturned until he had a full understanding of what was taking place with the patient and always involved the patient's family to complete his understanding. I never heard Bill start a presentation by launching into details of MR or CT. Bill quickly grasped the prime importance of the history and a complete physical examination.

As a teacher Bill exhibited a clarity of expression and was never given to bluffing. If he did not know, he had a nice knack of sharing the research for an answer with students and residents. He kept abreast of neurology, especially stroke neurology.

As a family man, Bill was the picture of dedication and caring. During his last few days, one of which I was fortunate to share in Halifax at his bedside, he was more interested in talking to and about his visitors, his wife and children than feeling sorry for his own inevitable fate from inoperable pancreatic cancer. He was a model patient.

Bill and I shared a passion for natural things, especially birds. Here, as in neurology, he was disciplined and demanding of accuracy. Together we wandered many of the beaches, islands and forests of Nova Scotia and were able to add two birds to the Nova Scotia list (Pacific Loon and Say's Phoebe). He did not rest until he had shared them with the experts at Dalhousie's biology department.

All who knew him will never forget Bill, his enthusiasm for life and his wise pronouncements in his deep baritone voice. He came into my life as a resident and quickly became a treasured life-time friend.

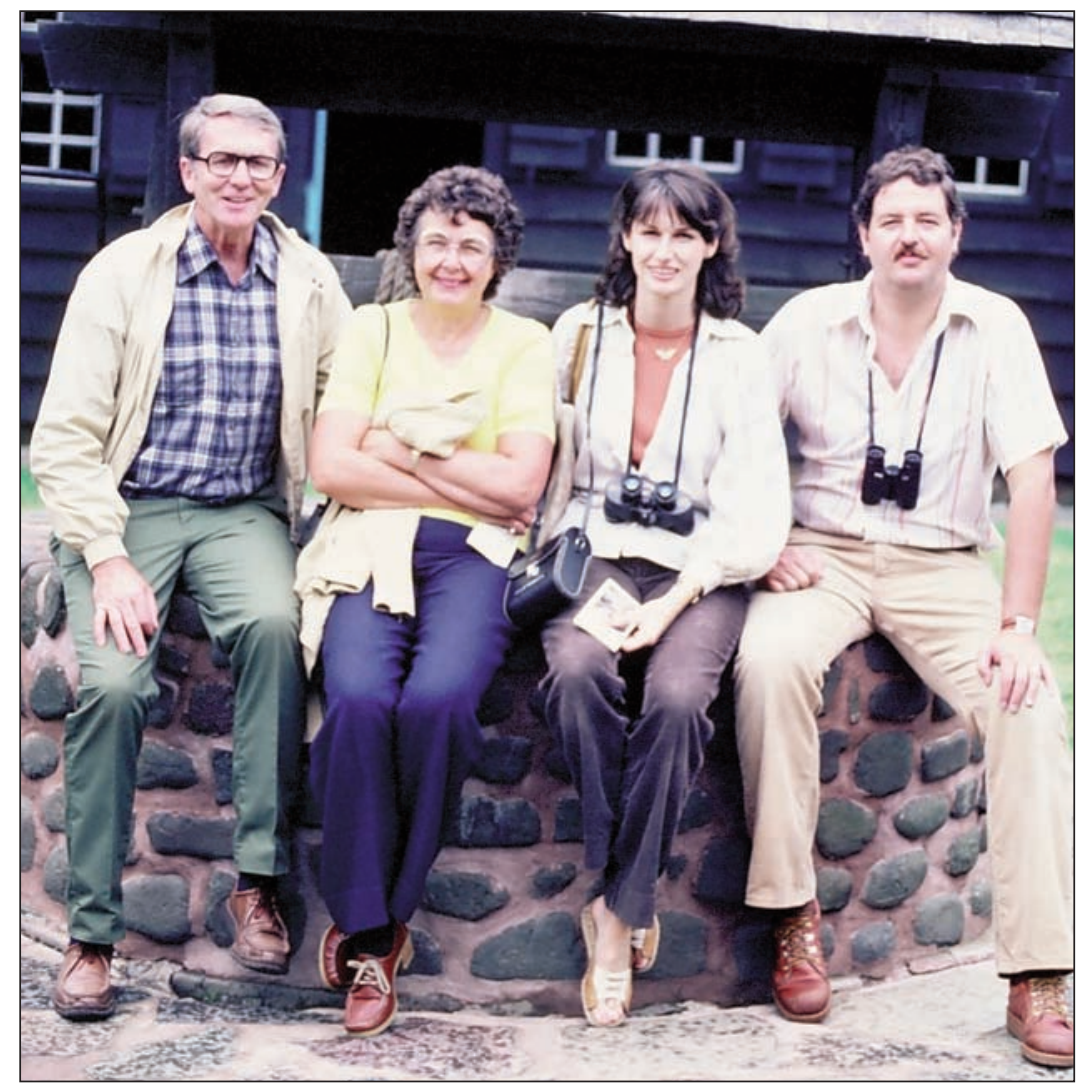

Figure: Bill and Joanne McCormick on a hiking trip with Kay and Henry Barnett. 